\title{
Preparation and Evaluation of Bioactivity of Porous Bioglass Tablets for Bone Tissue Regeneration
}

\author{
Rohith Kumar R. a, Sangeetha Ashok Kumar ${ }^{\text {b }}$ K. Periyasami Bhuvana ${ }^{a^{*}}$ \\ ${ }^{a}$ Department of Plastics Technology, Central Institute of Plastics Engineering \& Technology (CIPET), Chennai, Tamil Nadu, India. \\ ${ }^{b}$ Advanced Research School for Technology and Product Simulation (ARSTPS), Central Institute of Plastics Engineering \& Technology \\ (CIPET), Chennai, Tamil Nadu, India.
}

Received 02 June 2019; Accepted 18 August 2019

\begin{abstract}
The present study endeavors in the preparation and characterization of semi crystalline 45S5 bioglass $(\mathrm{BG})\left(\mathrm{SiO}_{2}-\mathrm{CaO}-\right.$ $\mathrm{P}_{2} \mathrm{O}_{5}$ ) through sol gel process. Dry press mold technique was used in the preparation porous BG tablets to examine the bioactivity through invitro studies. The synthesized BG powder was subjected to structural, morphological and mechanical characterization and the bioactivity was examined in vitro by immersing the BG tablet in the Simulated Body Fluid (SBF) solution. XRD pattern and the SEM micrographs revealed the semi crystalline nature of BG with spherical morphology. The elemental analysis confirms the presence of vital constituents required for Bone regeneration (Calcium, Phosphorous, Silica, and Sodium). The surface characterization of BG tablet reveals the pores structure of average pore size of $240 \mathrm{~nm}$ which contributed to the high surface activity resulting in formation of carbonated hydroxy apatite (HCAP) when immersed in SBF. The disintegration studies denoted the stabilization period was after 48 of immersion of BG tablets in SBF solution. The compressive strength measurement of the tablet also reveals the higher mechanical stability.
\end{abstract}

Keywords: Sol-gel Bioglass; Porous tablet; Bioactivity; Carbonated Hydroxy apatite; Bone Tissue Regeneration; Mechanical Stability.

\section{Introduction}

Multiple degenerative, inflammatory joint and bone diseases affected millions of people worldwide. A report in 2007 given by Bone and Joint Decade's association predicted that people over 50 years of age affected by bone diseases will double by 2020 [1]. Recent developments in tissue engineering in the field of orthopedic implants look forward to develop the regeneration capabilities of the host tissues with the help of bioactive materials in order to overcome the above stated problem [2]. A material is termed to bioactive, if it results in the bone formation between material and tissue under proper biological conditions.

The concept of "Bioactivity" is the basic principle of this Biomaterial. Bioactive glasses are a group of surface reactive glass-ceramic bioactive materials which are biocompatible. The bioactive nature of these glasses had facilitated to investigate them for implant device in the human body to promote bone regeneration. This Bioactive glasses (BAGs) were discovered in 1969 proved to be an alternative for interfacial bonding of an implant with host tissues. This has led a pathway for using slowly resorbable bioactive glasses as a biomaterials designed exclusively for the repair and replacement of damaged or diseased bones [3]. Bioactive glass is silicate based materials which contains calcium and phosphate along with it. Bioactive glass were biocompatible with the tissues resulting in formation of Hydroxy apatite (HAP) [4]. Safety of product is very important aspect of the medical field, so various studies were carried out to test the safety for clinical applications [5].

* Corresponding author: kpusha27@gmail.com

\section{doi http://dx.doi.org/10.28991/SciMedJ-2019-0103-1}

$>$ This is an open access article under the CC-BY license (https://creativecommons.org/licenses/by/4.0/).

(C) Authors retain all copyrights. 
Bioactive glasses are of different composition. Some classes of bio active glasses included are $45 \mathrm{~S} 5$ (45 mol\% $\mathrm{SiO}_{2}, 24.5 \mathrm{~mol} \% \mathrm{CaO}, 24.5 \mathrm{~mol} \% \mathrm{Na}_{2} \mathrm{O}$ and $6.0 \mathrm{~mol} \% \mathrm{P}_{2} \mathrm{O}_{5}$ ), $58 \mathrm{~S}$ glass $\left(60 \mathrm{~mol} \% \mathrm{SiO}_{2}, 36 \mathrm{~mol} \% \mathrm{CaO}^{2}\right.$ and $\left.4 \mathrm{~mol} \% \mathrm{P}_{2} \mathrm{O}_{5}\right), 70 \mathrm{~S} 30 \mathrm{C}\left(70 \mathrm{~mol} \% \mathrm{SiO}_{2}, 30 \mathrm{~mol} \% \mathrm{CaO}\right)$ and $\mathrm{S} 53 \mathrm{P} 4$ which is a bacterial growth inhibiting bioactive glass $\left(53 \mathrm{~mol} \% \mathrm{SiO}_{2}, 23 \mathrm{~mol} \% \mathrm{Na}_{2} \mathrm{O}, 20 \mathrm{~mol} \% \mathrm{CaO}\right.$ and $4 \mathrm{~mol} \% \mathrm{P}_{2} \mathrm{O}_{5}$ ). Among the above stated different composition of Bioactive glasses 45S5 which has FDA approval are now being used intraorally as a bone grafting materials. From the research activates it is noted that 45S5 has the capability to initiate the form HCAP (Hydroxy carbonated apatite) in a time period not more than 2 hours, also has an excellent binding with tissues. The formation of HCAP layer depends on the crystallinity of bioglass [5].

The two common processes for the formation of bioactive glass are melt quenching and sol-gel synthesis. In meltquenching Sodium carbonate $\left(\mathrm{Na}_{2} \mathrm{CO}_{3}\right)$ and calcium carbonate $\left(\mathrm{CaCO}_{3}\right)$ added together with ammonium dihydrogen phosphate $\left(\mathrm{NH}_{4} \mathrm{H}_{2} \mathrm{PO}_{4}\right)$ and silica $\left(\mathrm{SiO}_{2}\right)$ was heated to a high temperature followed by quenching. The dried samples were grounded, pressed and immersing into simulated body fluid [6].

$\mathrm{SiO}_{2}-\mathrm{CaO}-\mathrm{P}_{2} \mathrm{O}_{5}$ composition bioactive glass was synthesized by sol-gel technique which required lower temperature compared to the convention melt quench method [7]. Literature reviews suggested that glasses made by sol-gel technique has increased bioactivity[8]. Sol-gel method is preferred over melt-casting due to the following reasons: lower fabrication temperature, which has prominent role on the cost and the quality of the product, better control on composition and homogeneity, and synthesis of nano sized bioglass particles results in higher surface area, which increases the dissolution rate in body fluid and might contribute to the raise in bioactivity of the resultant material. Additional this higher surface area support to the fact of increase in hydroxyapatite (HAP) or hydroxy carbonate apatite (HCAP) formation, which is vital for preparing a suitable environment for attachment and differentiation of stem cells. Thus the synthesis methodology of the biomaterials has an important aspect in determining the properties and formation of the HAP/HCAP layer.

Hence sol-gel method was adopted in this work for the synthesis of bioglass. Many reports have indicated bulk crystalline bioactive glass-ceramics tends to show less bioactive than their amorphous counterparts while complete amorphous showed faster disintegration. Therefore this work was aimed in preparing semi-crystalline bioglass by solgel method. The novelty of the work lies in the fact of obtaining semi-crystalline bioglass with $20 \%$ crystallinity indicating more amorphous nature which might support for the rapid formation of HAP layer along with the sodium combeite which acts as a glass network modifier promotes the precipitation and crystallization of HAP.

\section{Materials and Methods}

\subsection{Synthesis of Bioglass}

45S5 bio active glass was synthesized by conventional sol-gel method using the following chemical precursors, Tetraethyl orthosilicate $\mathrm{Si}\left(\mathrm{OC}_{2} \mathrm{H}_{5}\right)_{4}$ (TEOS), triethyl phosphate PO $\left(\mathrm{C}_{2} \mathrm{H}_{5}\right)_{3}$ (TEP), Calcium Nitrate tetrahydrate Ca $\left(\mathrm{NO}_{3}\right)_{2} \cdot 4 \mathrm{H}_{2} \mathrm{O}$ and Sodium Nitrate $\mathrm{NaNO}_{3}$ from Sigma Aldrich. The systematic procedure is depicted in the Figure 1. The above-mentioned precursors were dissolved in the acidic medium of $0.1 \mathrm{M}$ of $\mathrm{HNO}_{3}$ such that the molar ratio between the aqueous acidic solution and the chemical precursors was 10. Initially the acidic medium (13ml) was magnetically stirred at ambient temperature and TEOS $(5.8 \mathrm{ml})$ and TEP $(0.5 \mathrm{ml})$ were added to the solution at half an hour gap and continuously stirred until a clear solution was obtained. After 30mins, $\mathrm{NaNO}_{3}$ powder (2.33g) was added to the solution and stirred until complete dissolution. Finally, the $\mathrm{Ca}\left(\mathrm{NO}_{3}\right)_{2} .4 \mathrm{H}_{2} \mathrm{O}$ powder $(3.58 \mathrm{~g})$ was added and resultant solution was stirred for 1 hour to obtain a transparent sol. The sol was aged for 12 hours at room temperature to make the hydrolysis of polycondensation fully react, to obtain a transparent gel which was heat treated at $60^{\circ} \mathrm{C}$ for 12 hours and $200^{\circ} \mathrm{C}$ for 5 hours subsequently to remove excess of water. A white glassy powder obtained was dried $700^{\circ} \mathrm{C}$ for 2 hours followed by which a powder of bioactive glass was obtained and characterized $[9,10]$.

\subsection{Preparation of Bioglass Tablets}

The bioglass powder so obtained was made into a cylindrical tablet of $15 \mathrm{~mm}$ diameter through dry pressing moulding technology by applying 10ton pressing load. Figure 2 depicts the pressed bioactive tablets, which was further subjected to in vitro bioactive analysis. 


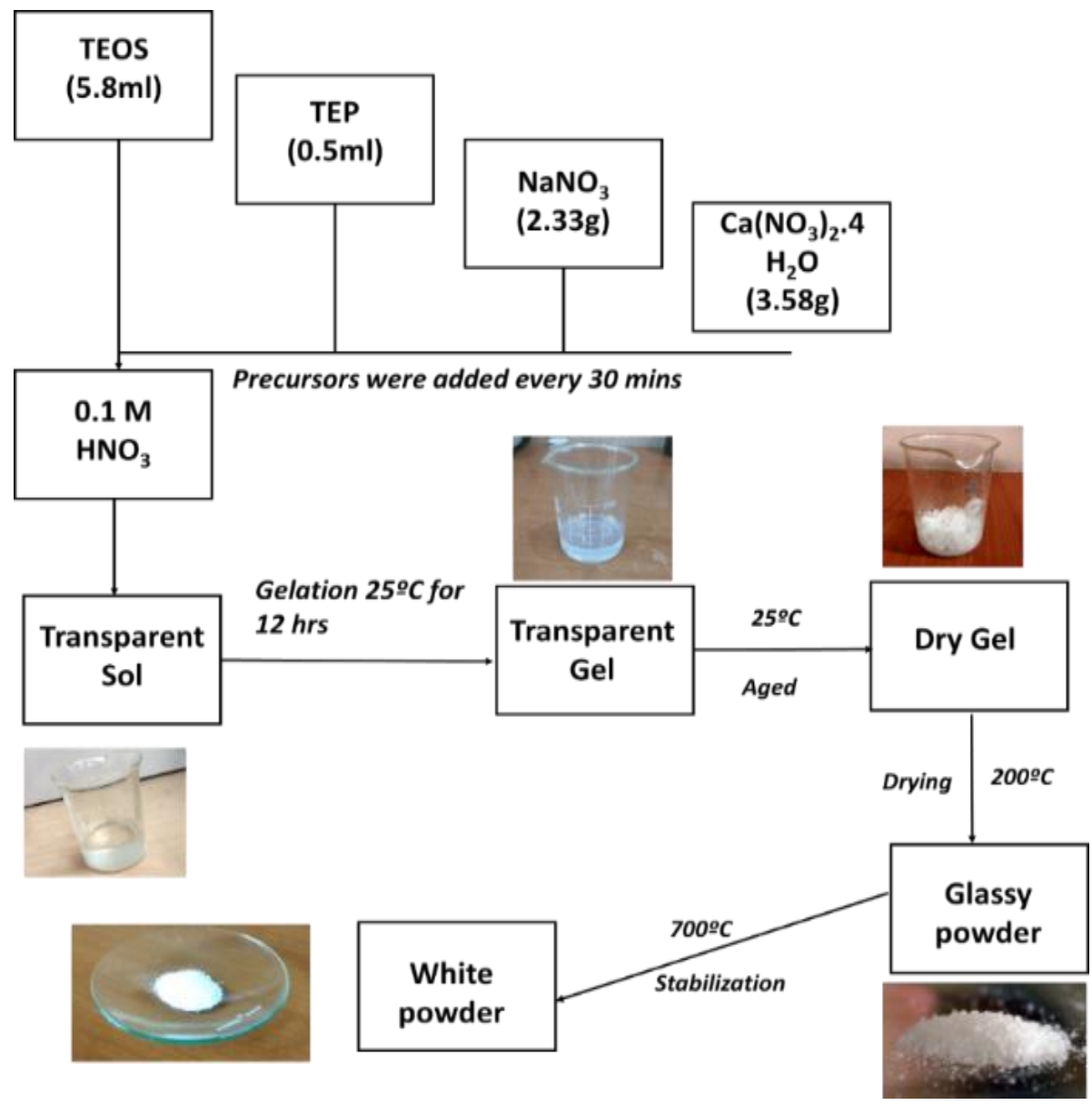

Figure 1. Synthesis of bioglass through sol gel route
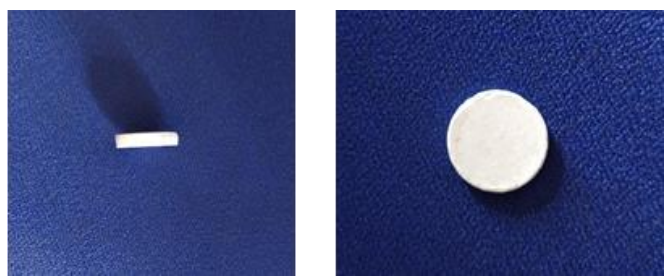

Figure 2. Dry pressed bioglass tablets

\subsection{Preparation of Simulated Body Fluid (SBF)}

The in vitro bioactive evaluation of the sol derived bioglass was done in Simulated Body Fluid (SBF) solution. The composition of SBF solution is analogous to that of the human plasma. SBF solution was prepared using Kokubo's method. It was prepared by the dissolution of $\mathrm{NaCl}, \mathrm{KCl}, \mathrm{K}_{2} \mathrm{HPO}_{4} \cdot 3 \mathrm{H}_{2} \mathrm{O}, \mathrm{MgCl}_{2} \cdot 6 \mathrm{H}_{2} \mathrm{O}, \mathrm{CaCl}_{2}$ and $\mathrm{Na}_{2} \mathrm{SO}_{4}$ in redistilled water maintaining buffer at $\mathrm{pH} 7.4$ with the assistance of tris(hydroxymethyl) amino methane $\left(\mathrm{HOCH}_{2}\right)_{3} \mathrm{CNH}_{2}$ and $\mathrm{HCl}[11]$.

\subsection{Characterization of Bioactive Glass}

The structural confirmation of the bioactive glass \& formation of HAP was studied using Fourier Transformed Infrared (FTIR) spectra under ATR condition, using Nicolet iS5-6700 model with wavenumbers ranging from $4000 \mathrm{~cm}^{-1}$ to $500 \mathrm{~cm}^{-1}$. Rigaku MiniFlex XRD model using a monochromatic copper radiation $\left(\mathrm{CuK}_{\alpha}\right)$ of wavelength $\lambda$ $=1.54 \AA$ was used to evaluate the crystallinity of bioglass \& detect the growth of HAP. The diffractograms were recorded in steps of $0.02^{\circ}$ in a range of diffraction angles $(2 \Theta)$ between $10^{\circ}$ and $80^{\circ}$. Particle Size distribution for the sol-gel derived bioactive glass was measured using MALVERN particle size analyzer at ambient condition with a count rate of $172 \mathrm{kcps}$. The size and shaped of the synthesized bioglass and the Surface morphology of the bioglass tablets before and after immersion in SBF were studied using Field Emission Scanning Electron Microscopy (FESEM) - FEI Quanta 200 Model SEM. 


\section{Results and Discussion}

\subsection{Elemental and Structural Characterization of BG Powder}

Figure 3 displays the FTIR spectrum of Bioglass. In the FTIR spectrum, the two bands at 521 and $539 \mathrm{~cm}^{-1}$ was attributed to $\mathrm{PO}_{4}$ bending vibration and the strong band at $1035 \mathrm{~cm}^{-1}$ was caused by $\mathrm{PO}_{4}$ symmetric stretching vibration. The small peak at 575 and $615 \mathrm{~cm}^{-1}$ refers to $\mathrm{P}-\mathrm{O}$ bonds, which shows a crystalline phosphate-rich phase. Two small double peaks at 669 and $698 \mathrm{~cm}^{-1}$ are correlated with the symmetric stretching of Si-O-Si in the crystalline silicate (9). The band emerges at 887 and $925 \mathrm{~cm}^{-1}$ is associated to the $\mathrm{Si}-\mathrm{O}$ with one non-bridging oxygen ( $\mathrm{Si}-\mathrm{O}-$ $\mathrm{NBO}$ ) per $\mathrm{SiO}_{4}$ tetrahedron which is formed through the presence of the glass network modifier, creating Si-O groups. At $1453 \mathrm{~cm}^{-1}$ a small broad peak is seen which can be assigned to the $\left(\mathrm{CO}_{3}{ }^{2-}\right)$ band of carbonates adsorbed on surfaces due to high reactive surface [9].

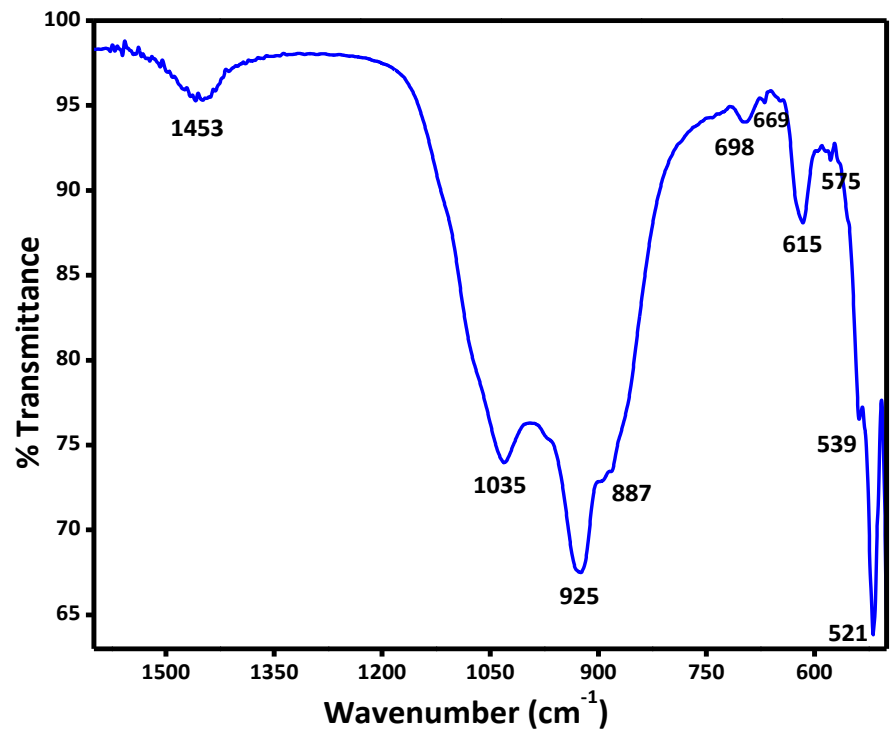

Figure 3. FTIR Spectrum of Sol-Gel Derived 45S5 Bioactive

Figure 4.a shows the X-Ray diffraction pattern of sol-gel derived bioactive glass. The XRD pattern reveals the amorphous nature of $45 \mathrm{~S} 5$ bioactive glass with crystalline sodium calcium silicate phases. Among them, combeite $\mathrm{Na}_{2} \mathrm{Ca}_{2} \mathrm{Si}_{3} \mathrm{O}_{9}$ (ICDD PDF \#22.1455) is the prominent one. The formation of the combeite phase is associated to the heat treatment performed at $700^{\circ} \mathrm{C}$ during the stabilization.

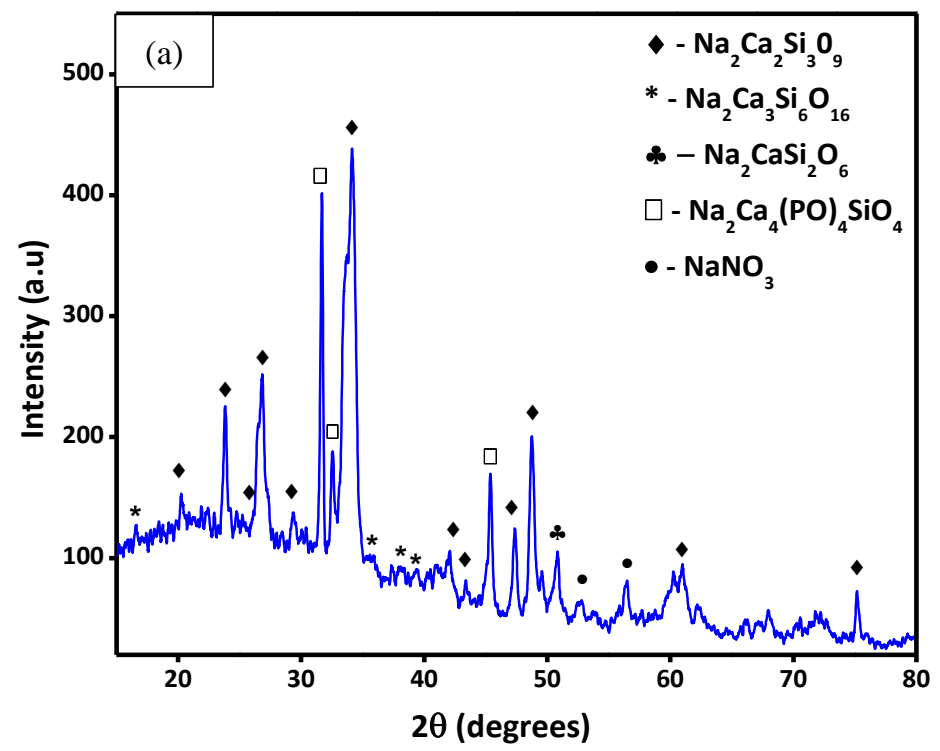




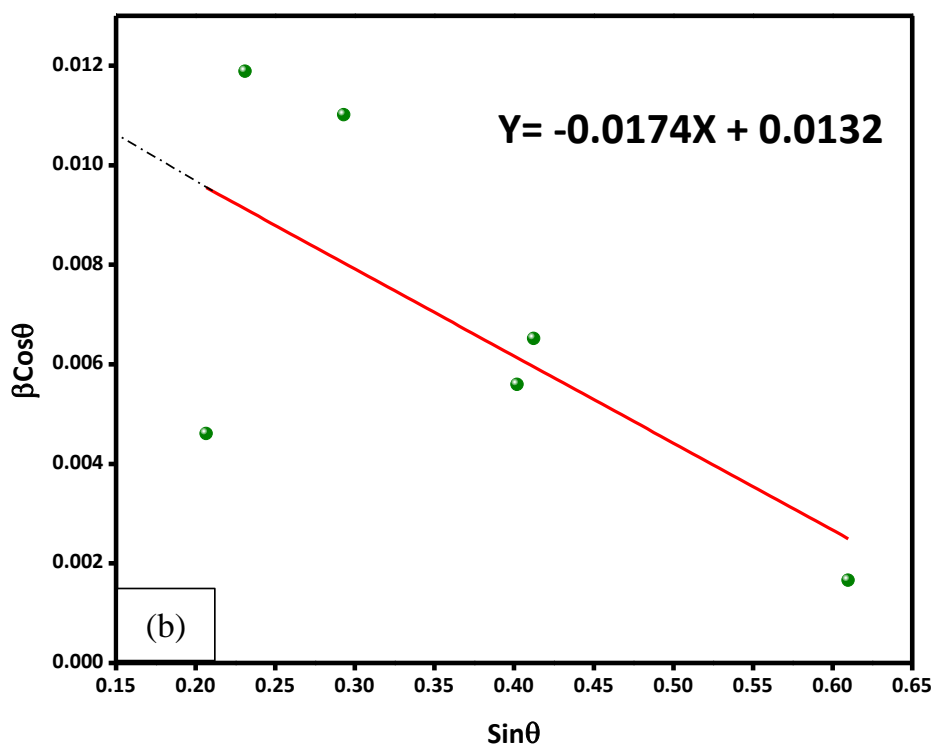

Figure 4. (a) X-Ray Diffraction of 45S5 Bioactive Glass; (b) W-H Plot

This is the characteristic structure of the bioactive glass synthesized by the sol-gel process. Heat treatment at high temperature $\left(700^{\circ} \mathrm{C}\right)$ for 2 hours of time had led to the formation of the crystalline apatite-like phosphorous-rich phase $\mathrm{Na}_{2} \mathrm{Ca}_{4}\left(\mathrm{PO}_{4}\right)_{2} \mathrm{SiO}_{4}$ (ICDD PDF\# 32. 1053) [12]. Low intensity Sodium nitrate peak (ICDD PDF\#036-1474) was also identified to be present in the bioglass. XRD result infers the presence of oxides of silica, sodium, calcium and Phosphorous. The degree of crystallinity was determined to be $19.40 \%$, hence the obtained bioglass was considered to be Semi-crystalline. The Deconvoluting size and strain broadening were evaluated using Williamson -Hall plot (Figure 4.b) The strain factor $\left(\beta_{\mathrm{e}}\right)$ was determined as 0.0174 and average crystallite size was calculated as $10.41 \mathrm{~nm}$. The materials with small size crystalline (less than 100nm) is stated to be amorphous. Here amorphous is attributed due to disorder of crystal in macro scale which is also supported by lesser degree of crystallinity [13].

\subsection{Morphological Characterization of BG Powder}

The surface characteristics \& size of the bioglass were studied using FESEM \& PSA respectively. Figure 5 depicts the particle size distribution curve of $0.5 \mathrm{mg}$ of synthesized bioactive glass dispersed through ultrasonication for 15 minutes in $3 \mathrm{ml}$ of deionized water
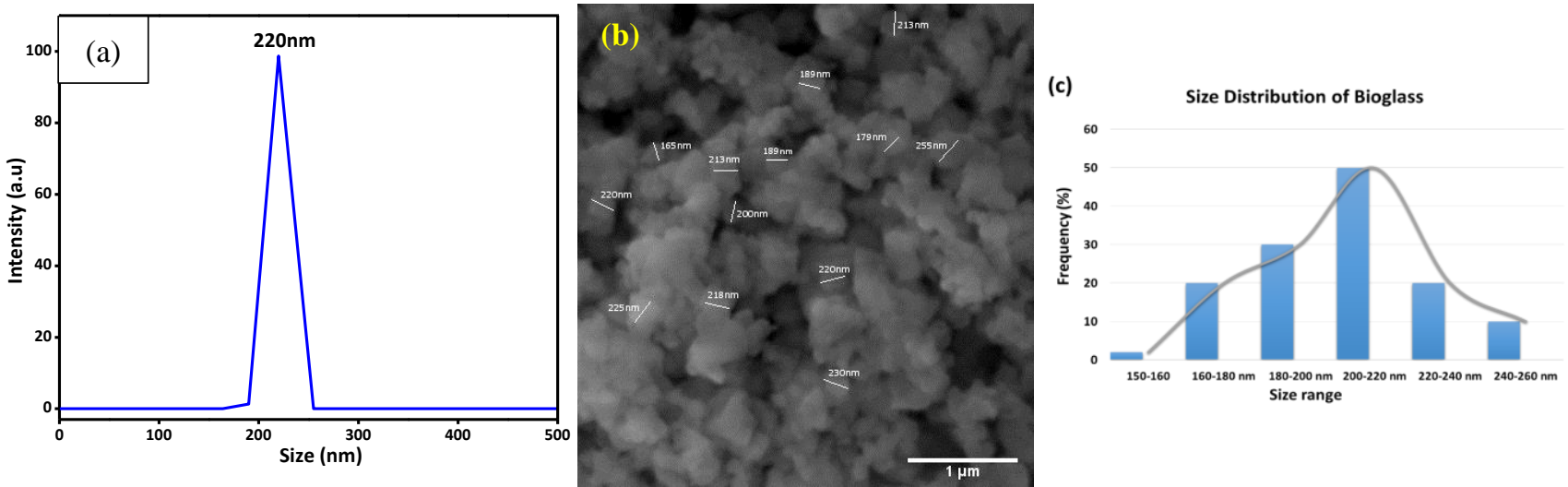

Figure 5. (a) Particle Size Analysis; (b) 25kX Magnification; (c) Size distribution of bioglass

From the size distribution intensity data, it is inferred that the particle size distribution ranges from 190-250nm with maximum intensity peak obtained at $220 \mathrm{~nm}$ signifying the average particle size of the $45 \mathrm{~S} 5$ bioactive glass. The appearance of single maxima peak indicates the uniform size distribution of particles. The occurrence of smaller particle size induce high surface reactivity, which will attribute to the faster formation of HAP Layer[14]. Figure 5(b) depicts morphology of the sol-gel derived bioglass. It is inferred from the micrograph that the synthesized bioglass are spherical in shape with circular morphology. The average size of the particle was measured to be $208 \mathrm{~nm}$ which 
coincides with the particle size obtained from the PSA analysis. It is clearly visible from the SEM image that there is more agglomeration of the particles from which attributes to the high surface reactivity of BG nanoparticles. The size distribution (Figure 5(c)) obtained from micrograph was observed to be well matches with the particle size analysis where the maximum size distribution was obtained in the range of 200 to $220 \mathrm{~nm}$.

\subsection{Compositional Analysis}

In order to study the elemental composition of bioglass, it was subjected to energy dispersive spectroscopy (EDS). From EDS (Figure 6), the presence of the essential elements (silica, sodium, calcium \& phosphorous) are evident, which confirms that the synthesized nanomaterial is Bioglass. Also, the bioglass is observed to be oxygen rich. The presence of $\mathrm{Au}$ and $\mathrm{Pd}$ element in the EDS spectrum is due to the conductive coating done for the SEM analysis.

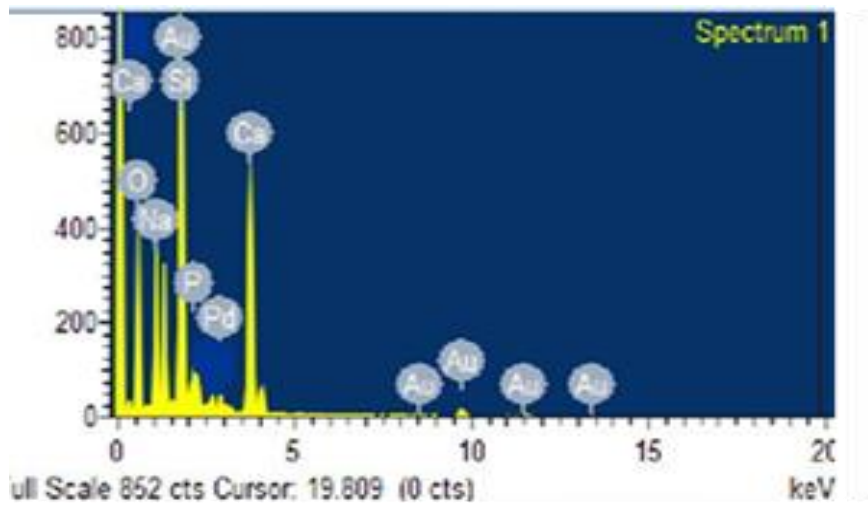

Figure 6. EDS spectrum of bioglass

\subsection{Mechanical Characterization of Compressed BG Tablets}

\subsubsection{Density}

Cylindrical pellet of $15 \mathrm{~mm}$ diameter and thickness of $3 \mathrm{~mm}$ was obtained from dry press mold which weighed 0.9 $\mathrm{gm}$. The density of the pellet was estimated to be $1.6 \mathrm{gm} / \mathrm{cc}^{3}$.

\subsubsection{Compressive Strength}

The mechanical strength of the tablet was studied using axial compressive strength. Figure 7 shows the compressive stress strain curve measured at room temperature. From $\mathrm{S}-\mathrm{S}$ curve the ultimate compressive strength and modulus were determined as 56.63 $\mathrm{MPa}$ and $2649 \mathrm{MPa}$, which are adequate to replicate the bone strength. The obtained compressive strength is higher than previously reported data as far as our survey is considered [10]. The mechanical stability in the tablet was attributed due to the semi-crystalline nature BG and porous structure in the tablet.

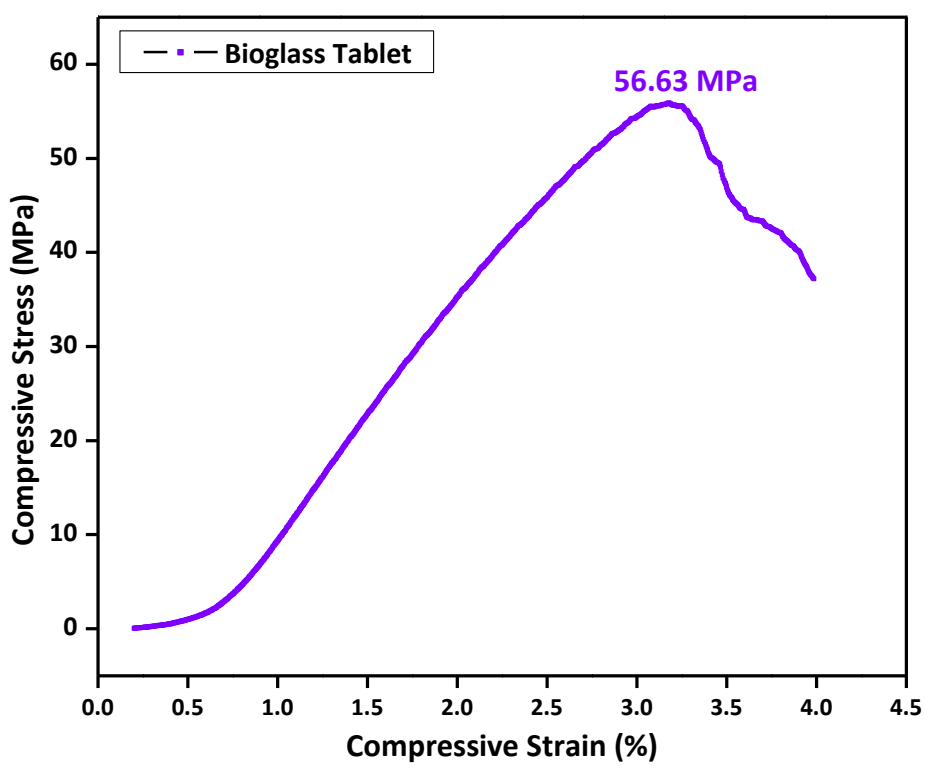

Figure 7. Compressive Stress - Strain Curve of Bioglass Tablet 


\subsubsection{Disintegration Studies}

In order to study the resistance towards disintegration of the tablets, the prepared tablet was immersed in $80 \mathrm{ml}$ of SBF for a stipulated period and weight loss as a function of time was measured. The weight loss behavior of BG tablet immersed in SBF solution is shown in Figure 8. It is observed that that the weight of BG tablet initially increased (upto to 8 hours) because of the absorption of the solution by its porous structure. Subsequently, slight decrease in weight was observed after 12 hours upto $0.2 \%$ and the maximum weight loss of $1.3 \%$ was observed after 48 hrs. After 48 hours, the weight of BG tablets remains stable, from which it is evident that no significant disintegration of bioglass particles was observed. It can be inferred that, the degradation and deposition of material had reached to a dynamic balance [10].

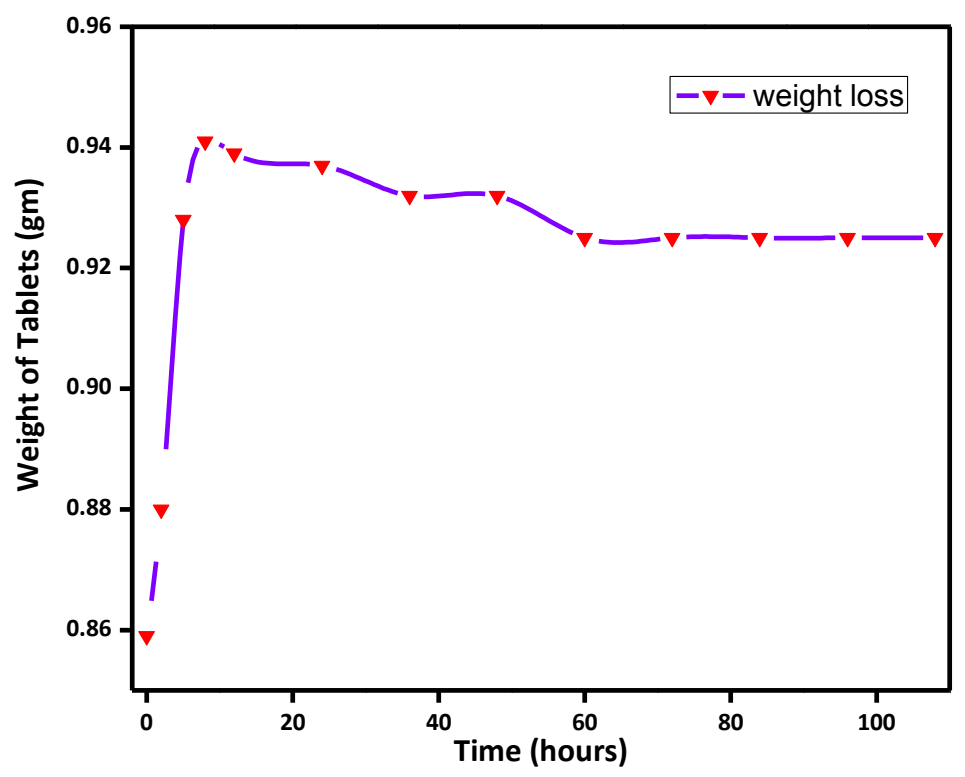

Figure 8. Weight loss study of the BG Tablet

\subsection{In Vitro Reactivity on Nanoscale and Biocompatibility}

The kinetics of hydroxyapatite formation on the 45S5 bioglass tablet was monitored using FT-IR measurements, XRD characterization and SEM analysis. The SBF immersed pellet were taken out at certain time period (1, 2 \& 3 weeks) and dried at $25^{\circ} \mathrm{C}$ overnight and then analyzed for its surface reactivity.

\subsubsection{FT-IR Analysis}

Figure 9 represents the significant changes in the bonds of the bioglass tablet. After immersion in SBF, $\mathrm{P}-\mathrm{O}$ bonds which represent HAP $\left(\mathrm{Ca}_{10}\left(\mathrm{PO}_{4}\right)_{6}(\mathrm{OH})_{2}\right)$ crystallization, become evident through the growth of peak around $1025 \mathrm{~cm}^{-1}$. As the stretching $\mathrm{P}-\mathrm{O}$ bond at $1025 \mathrm{~cm}^{-1}$ is superimposed on the $\mathrm{Si}-\mathrm{O}$ stretching bonds corresponding to the biomaterial; it becomes difficult to discriminate them [15]. From the above spectrum it is evident that rapid exchange of protons $\mathrm{H}_{3} \mathrm{O}^{+}$from the SBF with $\mathrm{Ca}^{2+}, \mathrm{Na}^{+}$ions in bioglass to form the Si-OH groups, followed by loss of soluble silica as $\mathrm{Si}(\mathrm{OH})_{4}$ by breaking of Si-O-Si bridging links which is the reason behind the diminishing of the Si-NBO band [16]. The growth of carbonate peak around $1300 \mathrm{~cm}^{-1}$ indicated that the formed HAP are carbonated HAP (HCAP). 


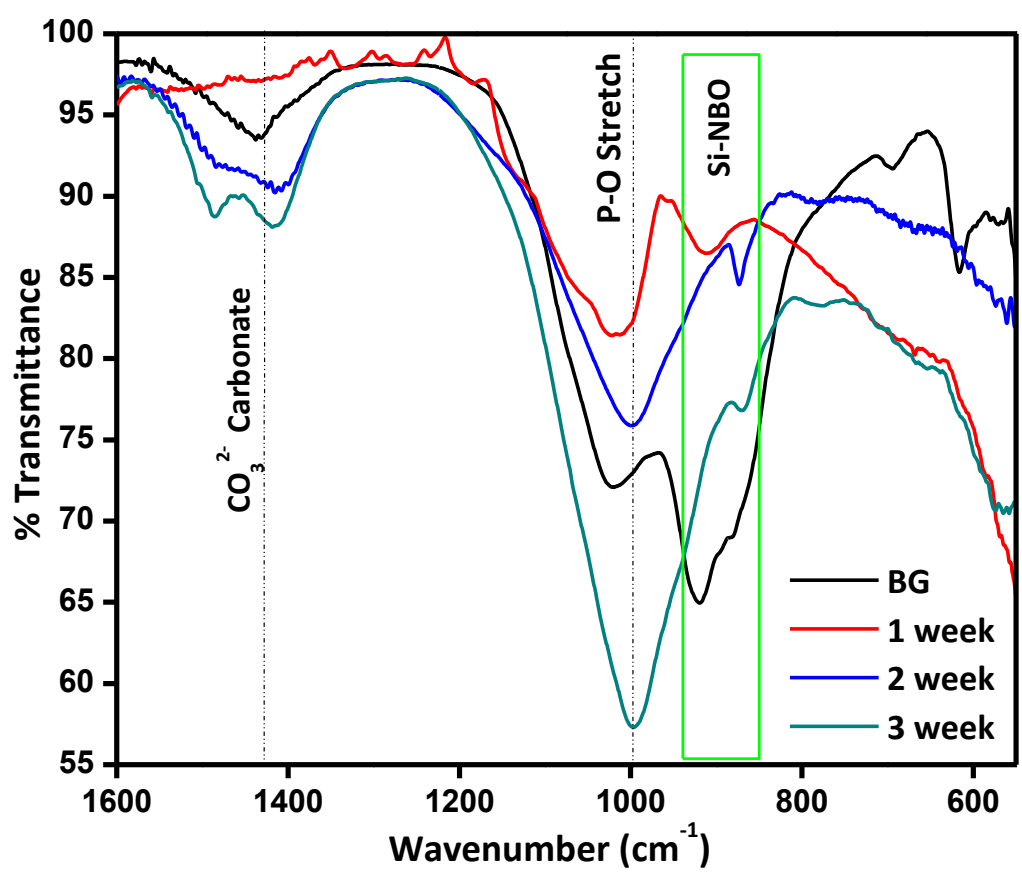

Figure 9. FTIR Spectrum of SBF immersed Bioglass Pellet

Table 1. Ratio of P-O bond to Si-NBO Bond

\begin{tabular}{ll}
\hline Days in SBF Solution & Ration of P-O to Si-NBO \\
\hline 0 days & 0.75 \\
7 days (1 week) & 1.39 \\
14 days (2 weeks) & 1.71 \\
21 days (3 weeks) & 2.14 \\
\hline
\end{tabular}

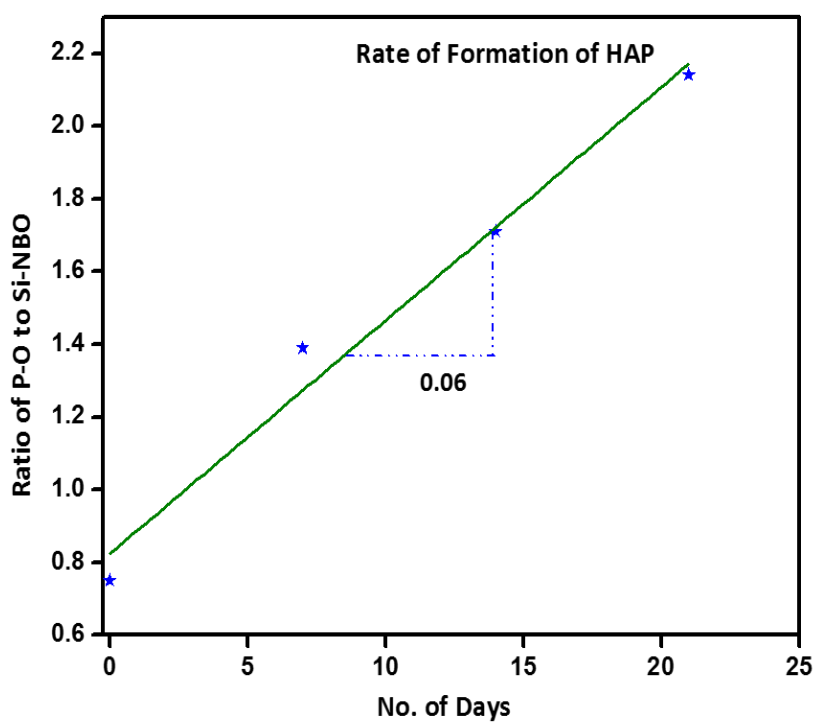

Figure 10. Rate of Apatite Formation

As shown in Table 1, this ratio P/Si becomes relatively increasing which an appropriate sign for HCAP formation reaction in the gel-derived $45 \mathrm{~S} 5$ bio glass. To estimate the growth rate of the HCAP formation a graph is plot between the time period and P-O to Si-NBO ratio. From the graph (Figure 10) the rate of formation of HCAP is estimated to be 0.06 which is nearly to the already reported data $(0.08)[15]$. 


\subsubsection{XRD Analysis}

The XRD pattern of the samples soaked in SBF for $1,2 \& 3$ weeks are given in the Figure 11 . Peak around $19.8^{\circ}$ signifies the PVA content which is added during the formation of pellet as a binder. During the first week the XRD pattern is amorphous in nature. Because the sodium combeite are restructured by the release of the sodium ions when interacts with the SBF and results in formation of the silica gel. Appearance of the peak around $35^{\circ}, 49^{\circ}$ and $59^{\circ}$ denotes the formation of the Calcium phosphate [16].

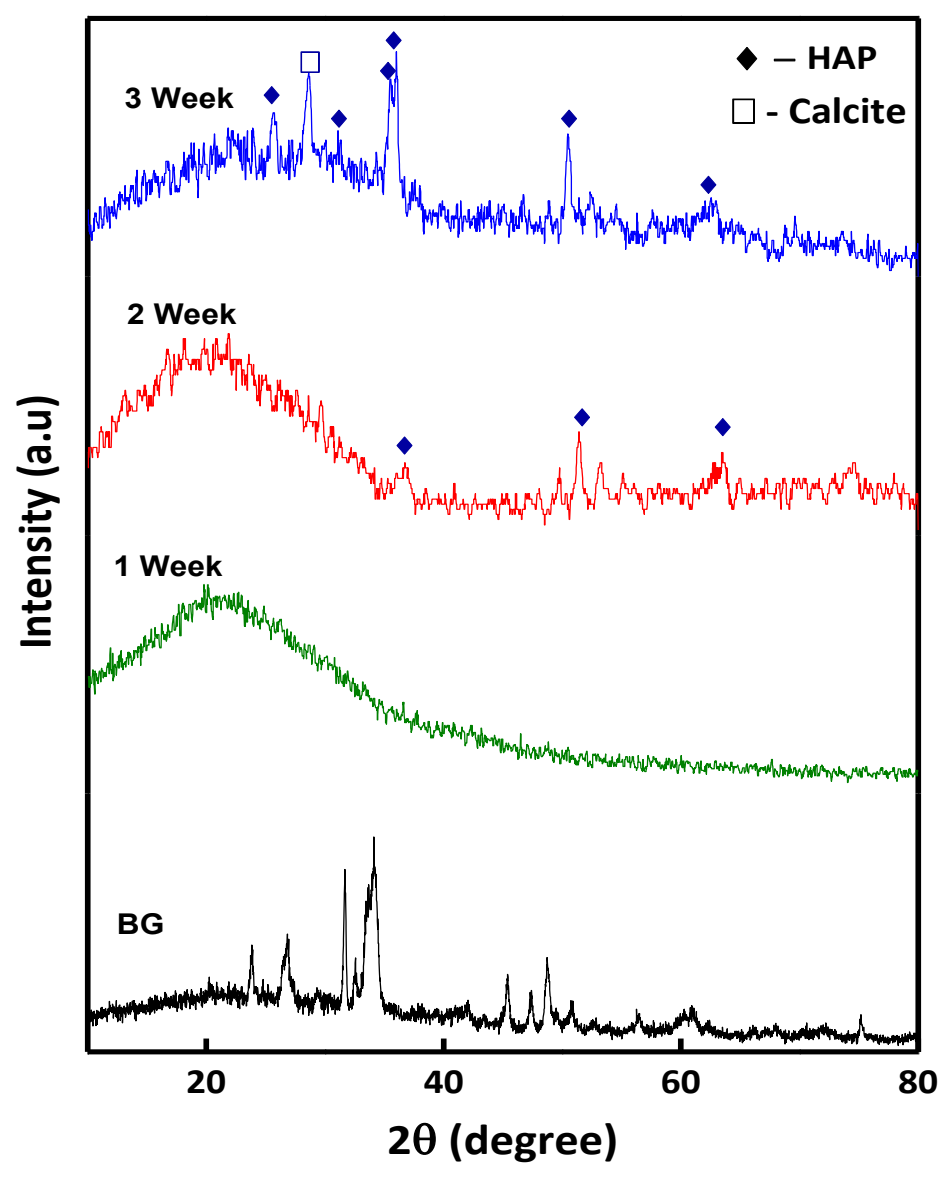

Figure 11. Diffractogram of SBF immersed Bioglass Pellet

The diffractogram of $2^{\text {nd }}$ week is also amorphous in nature because of the formation of amorphous calcium phosphate layer which is the base layer for the HCAP growth. The X-Ray diffraction of the $3^{\text {rd }}$ week is tending to be crystalline in nature signifies the growth of the HCAP layer by utilization of the amorphous Ca-P layer. Appearance of peak around $25^{\circ}$ and $32^{\circ}$ along with intensification of the peaks around $35^{\circ}$ and $49^{\circ}$ denotes the HCAP formation (ICDD 9432) increases with the soaking time confirming the successful deposition of HCAP on the BG pellets. The reactions kinetics of the $\mathrm{BG}$ pellets showed a formation of calcite which was detected with a peak at $28.7^{\circ}$ (JCPDS \#47-1743), likely due to the high surface area of the particles [16].

\subsubsection{SEM with EDS}

Figure 13 depicts the FESEM image of the bioglass tablets before and after immersion in SBF solution. From the micrograph it is estimated that the pore size of the tablet ranges from $150 \mathrm{~nm}$ to $380 \mathrm{~nm}$ and average pore size of $240 \mathrm{~nm}$, which reveals the porous nature of the surface (ref insert of Figure 12.a). It is evident from the micrographs of the tablets the growth of HCAP after immersion in SBF solution exhibited a smooth surface due to the growth of apatite layer as supported by FTIR and XRD results. Also, the growth of HCAP layer is observed to be increasing over the period of time. The porous nature of the bioglass tablet surface supports the growth of HCAP. 

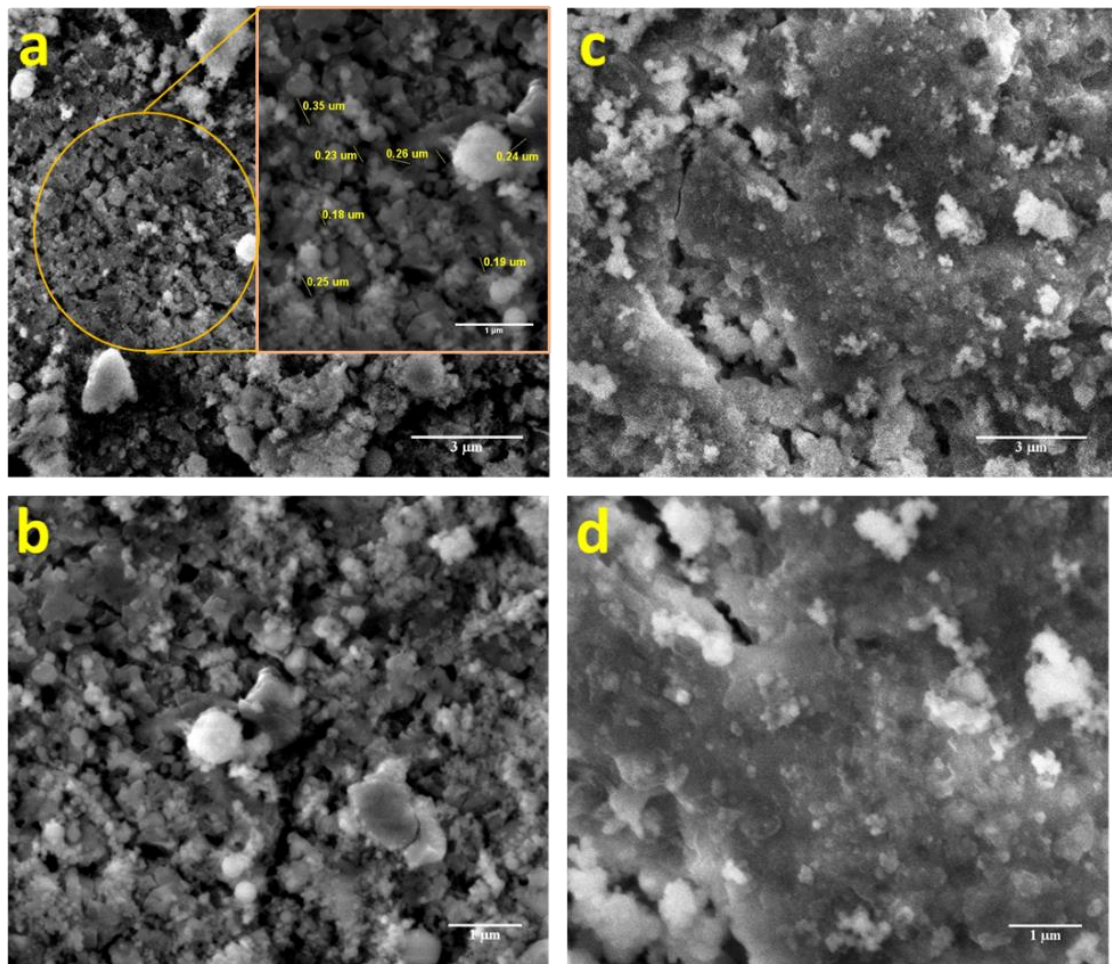

Figure 12. SEM image of bioglass tablet (a) before immersion; (b) after 1 week immersion; (c) after 2 week immersion and (d) after 3 week immersion in SBF solution

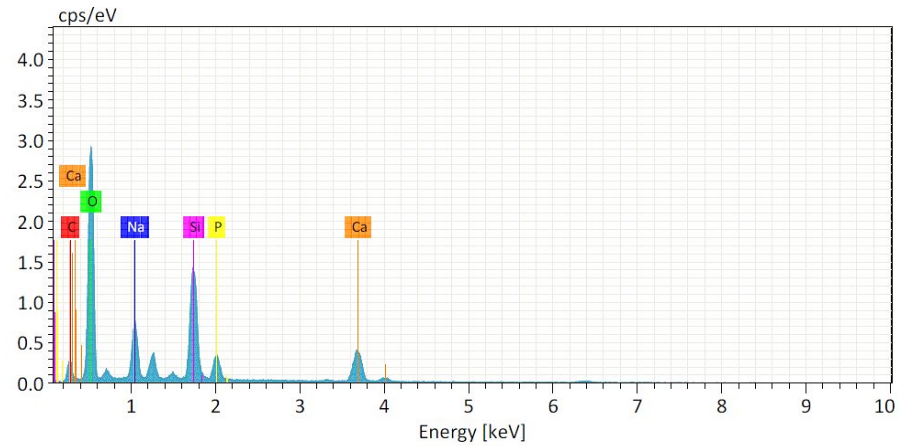

$\begin{array}{lllllll}\text { Spectrum } & \mathrm{C} & \mathrm{O} & \mathrm{Na} & \mathrm{Si} & \mathrm{P} & \mathrm{Ca}\end{array}$ Test $484 \quad 6.3352 .266 .28 \quad 16.883 .6914 .55$

Figure 13. EDS curve of Bioglass after immersion in SBF

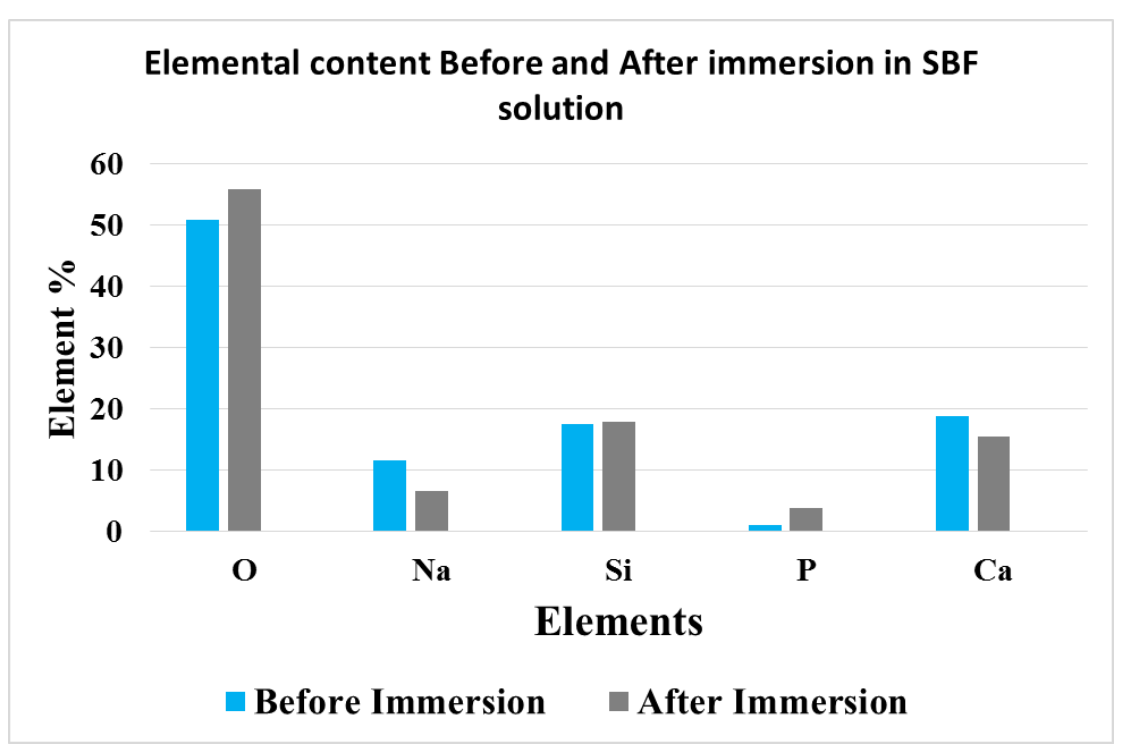

Figure 14. Quantitative Elemental Composition 
After incubated in SBF for 21 days, the surface of BGC particle became smoother and heavily agglomerated. Many small protuberances grew on the surface of BG clusters (Figure 12 (c\&d)).Quantitative elemental analysis denoted in Figure 14 obtained from the EDX data (Figures 6 and 13) indicated the increase of phosphorous by $73 \%$ denotes the growth if HCAP layer and the decrease of sodium content by $74 \%$ indicates the fact that the Na glass network modifier contributed to the precipitation of HCAP on the surface of BG particles after soaking in SBF.

\section{Conclusion}

Semi-crystalline 45S5 type bioglass was synthesized by sol gel method and made into tablet. The presence of major constituents of bioglass like sodium, calcium, phosphorus and silica was confirmed using FTIR, XRD and EDS analysis. The particle size of the bioglass was determined as around $200 \mathrm{~nm}$, contributing to higher surface area. The invitro bioactivity of the bioglass tablet was tested by immersing the BG tablet in SBF solution and analyzed using FTIR, XRD and SEM. The studies confirmed that the semi-crystalline nature, presence of sodium combite and the porous nature of bioglass tablet attributed to the growth of Carbonated hydroxy apatite (HCAP) on the surface of the tablet. The kinetics of the HCAP growth was analyzed through FTIR and observed the rate as 0.06 units / day. The bioglass tablet was also observed to be mechanically stable with the compressive strength and modulus of $56.63 \mathrm{MPa}$ and $2649 \mathrm{MPa}$ respectively which was attributed due to the semi-crystalline nature of BG nanoparticles and the pores present in the tablet. The sol derived 45S5 bioactive glass possess good rate of bioactivity and exhibits high mechanical strength. Hence this glass can be used in preparation of porous scaffolds using polymers by Electrospinning for enhanced bioactivity

\section{Acknowledgements}

I express my sincere thanks to All India Council for Technical Education (AICTE) for providing me financial support for my Post Graduation course.

\section{Declaration of Competing Interest}

The authors declare that they have no known competing financial interests or personal relationships that could have appeared to influence the work reported in this paper.

\section{Ethical Approval}

All procedures performed in studies involving human participants were in accordance with the ethical standards of the institutional and/or national research committee and with the 1964 Helsinki declaration and its later amendments or comparable ethical standards.

\section{References}

[1] Navarro, M., Michiardi, A., Castaño, O., \& Planell, J.. (2008). Biomaterials in orthopaedics. Journal of the Royal Society Interface, 5(27), 1137-1158. doi:10.1098/rsif.2008.0151.

[2] Rahaman, M. N., Day, D. E., Sonny Bal, B., Fu, Q., Jung, S. B., Bonewald, L. F., \& Tomsia, A. P. (2011). Bioactive glass in tissue engineering. Acta Biomaterialia, 7(6), 2355-2373. doi:10.1016/j.actbio.2011.03.016.

[3] Hench, L. L. (2013). Chronology of Bioactive Glass Development and Clinical Applications. New Journal of Glass and Ceramics, 03(02), 67-73. doi:10.4236/njgc.2013.32011.

[4] Hench, L. L. (2006). The story of Bioglass®. Journal of Materials Science: Materials in Medicine, 17(11), 967-978. doi:10.1007/s10856-006-0432-z.

[5] Wilson, J., Pigott, G. H., Schoen, F. J., \& Hench, L. L. (1981). Toxicology and biocompatibility of bioglasses. Journal of Biomedical Materials Research, 15(6), 805-817. doi:10.1002/jbm.820150605.

[6] Martin, R. A., Twyman, H., Qiu, D., Knowles, J. C., \& Newport, R. J. (2008). A study of the formation of amorphous calcium phosphate and hydroxyapatite on melt quenched Bioglass ${ }^{\circledR}$ using surface sensitive shallow angle X-ray diffraction. Journal of Materials Science: Materials in Medicine, 20(4), 883-888. doi:10.1007/s10856-008-3661-5.

[7] Li, R., Clark, A. E., \& Hench, L. L. (1991). An investigation of bioactive glass powders by sol-gel processing. Journal of Applied Biomaterials, 2(4), 231-239. doi:10.1002/jab.770020403.

[8] Peltola, T., Jokinen, M., Rahiala, H., Levänen, E., Rosenholm, J. B., Kangasniemi, I., \& Yli - Urpo, A. (1999). Calcium phosphate formation on porous sol - gel - derived $\mathrm{SiO} 2$ and $\mathrm{CaO}-\mathrm{P} 2 \mathrm{O} 5$ - $\mathrm{SiO} 2$ substrates in vitro. Journal of Biomedical Materials Research: An Official Journal of The Society for Biomaterials, The Japanese Society for Biomaterials, and the Australian Society for Biomaterials, 44(1), 12-21. doi: 10.1002/(SICI)1097-4636(199901)44:1<12::AID-JBM2>3.0.CO;2-E. 
[9] Faure, J., Drevet, R., Lemelle, A., Ben Jaber, N., Tara, A., El Btaouri, H., \& Benhayoune, H. (2015). A new sol-gel synthesis of 45S5 bioactive glass using an organic acid as catalyst. Materials Science and Engineering: C, 47, $407-412$. doi:10.1016/j.msec.2014.11.045.

[10] Chen, J., Zeng, L., Chen, X., Liao, T., \& Zheng, J. (2018). Preparation and characterization of bioactive glass tablets and evaluation of bioactivity and cytotoxicity in vitro. Bioactive Materials, 3(3), 315-321. doi:10.1016/j.bioactmat.2017.11.004.

[11] Kokubo, T., \& Takadama, H. (2006). How useful is SBF in predicting in vivo bone bioactivity? Biomaterials, 27(15), 29072915. doi:10.1016/j.biomaterials.2006.01.017.

[12] Hong, Z., Liu, A., Chen, L., Chen, X., \& Jing, X. (2009). Preparation of bioactive glass ceramic nanoparticles by combination of sol-gel and coprecipitation method. Journal of Non-Crystalline Solids, 355(6), 368-372. doi:10.1016/j.jnoncrysol.2008.12.003.

[13] Pozdnyakov, V. A. (2003). Generalized size-dependent structural states of materials with an ultrafine structure. Crystallography Reports, 48(4), 701-704. doi:10.1134/1.1595199.

[14] Shin, S., Song, I., \& Um, S. (2015). Role of Physicochemical Properties in Nanoparticle Toxicity. Nanomaterials, 5(3), 13511365. doi:10.3390/nano5031351.

[15] Pirayesh, H., \& Nychka, J. A. (2013). Sol-Gel Synthesis of Bioactive Glass-Ceramic 45S5 and itsin vitroDissolution and Mineralization Behavior. Journal of the American Ceramic Society, 96(5), 1643-1650. doi:10.1111/jace.12190.

[16] Mabrouk, M., Mostafa, A. A., Oudadesse, H., Mahmoud, A. A., \& El-Gohary, M. I. (2014). Effect of ciprofloxacin incorporation in PVA and PVA bioactive glass composite scaffolds. Ceramics International, 40(3), $4833-4845$. doi:10.1016/j.ceramint.2013.09.033. 